OPEN ACCESS

Edited by:

Xi Yang,

Fudan University, China

Reviewed by:

Hongzan Sun,

Shengjing Hospital of China Medical

University, China

Yuncong Liu,

Guizhou Provincial People's Hospital,

China

*Correspondence:

Fuquan Zhang

zhangfuquan3@sina.com

$\mathrm{Ke} \mathrm{Hu}$

huk@pumch.cn

${ }^{\dagger}$ These authors have contributed equally to this work

Specialty section:

This article was submitted to

Radiation Oncology,

a section of the journal

Frontiers in Oncology

Received: 16 December 2020

Accepted: 16 August 2021

Published: 01 September 2021

Citation:

Wang W, Liu X, Wang D, Ren K, Zhou Y, Zhou Z, Qiu J, Zhang F and Hu K (2021) The 100 Most Cited

Papers in Radiotherapy or

Chemoradiotherapy for Cervical

Cancer: 1990-2020.

Front. Oncol. 11:642018.

doi: 10.3389/fonc.2021.642018

\section{The 100 Most Cited Papers in Radiotherapy or Chemoradiotherapy for Cervical Cancer: 1990-2020}

\author{
Weiping Wang ${ }^{\dagger}$, Xiaoliang Liu ${ }^{\dagger}$, Dunhuang Wang, Kang Ren, Yuncan Zhou, Ziqi Zhou, \\ Jie Qiu, Fuquan Zhang* and Ke Hu* \\ Department of Radiation Oncology, Peking Union Medical College Hospital, Chinese Academy of Medical Sciences \& Peking \\ Union Medical College, Beijing, China
}

Objective: This work aims to analyze the 100 most cited papers in radiotherapy or chemoradiotherapy for cervical cancer.

Methods: The 100 most cited papers in radiotherapy or chemoradiotherapy between 1990 and 2020 were identified with Thompson Reuters Web of Science citation indexing on August 24, 2020. The publication years, source titles, countries/regions, total citations, and average citations per year were extracted from the Web of Science. The research type and research domain were classified by the authors.

Results: These 100 papers were cited a total of 28,714 times, and the median number of citations was 169.5 (ranging from 116 to 1,700 times). The most cited paper was "Concurrent cisplatin-based radiotherapy and chemotherapy for locally advanced cervical cancer" by Rose et al., with a total citation of 1,700 times. The International Journal of Radiation Oncology Biology Physics (40 papers), Radiotherapy and Oncology (14 papers), and the Journal of Clinical Oncology (12 papers) published the largest number of papers. USA (47 papers), Austria (18 papers), Canada (13 papers), and England (13 papers) contributed the largest number of papers. Image-guided adaptive brachytherapy (IGABT) had the largest number of papers (25 papers). Concurrent chemotherapy was the most cited research domain, with 10,663 total citations and 592.4 citations per paper.

Conclusion: In the present study, we conducted a bibliometric analysis of the 100 most cited papers in radiotherapy or concurrent chemoradiotherapy for cervical cancer in the past 30 years. IGABT and concurrent chemotherapy were the most cited research domains.

Keywords: cervical cancer, radiation therapy, bibliometric analysis (BA), concurrent chemoradiotherapy, imageguided adaptive brachytherapy 


\section{INTRODUCTION}

Cervical cancer is one of the most common cancers globally, especially in countries with a middle/low human development index (1). Radiotherapy or chemoradiotherapy plays an important role in the treatment of cervical cancer. Adjuvant radiotherapy/concurrent chemoradiotherapy (CCRT) is performed in early-stage cervical cancer patients with risk factors. Definitive CCRT is the standard treatment approach in patients with locally advanced cervical cancer (LACC). Palliative/ salvage radiotherapy is conducted in patients with stage IVB or recurrent disease (2). The staging and treatment strategy have changed dramatically in the past three decades. The FIGO staging system was revised in 1994, 2009 (3), 2014 (4), and 2018 (5). Nodal status is incorporated into stage IIIC disease in the last FIGO staging system (5). The treatment strategy for LACC changed from single radiotherapy to concurrent chemoradiotherapy. Brachytherapy was transformed from twodimensional brachytherapy to MRI-based image-guided adaptive brachytherapy (IGABT). External beam radiation therapy has changed from conventional radiotherapy to intensity-modulated radiation therapy (IMRT) or conformal radiation therapy.

It is a challenging task for researchers to identify the most influential work in a specific area. Bibliometric analysis, also known as citation analysis, is one way to identify the most influential papers. The citation frequency of a paper can reflect its impact. In the present study, we performed a bibliometric analysis of the 100 most cited papers in radiotherapy or chemoradiotherapy for cervical cancer to identify the most influential work in this area.

\section{METHODS}

The Thompson Reuters Web of Science citation indexing database was used to identify the most cited papers. The bibliometric analysis was performed on August 24, 2020. The database selected was the Web of Science Core Collection. The time span was 1990-2020. No restriction was placed on the language or document types. The search strategy was as follows: Title $=($ Cervical NEAR $/ 3$ Cancer OR Cervical NEAR $/ 3$ Neoplasm ${ }^{\star}$ OR Cervical NEAR/3 Carcinoma ${ }^{\star}$ OR cervix NEAR/ 3 cancer OR Cervix NEAR/3 Neoplasm ${ }^{\star}$ OR cervix NEAR/3 carcinoma $^{\star}$ ) AND Title $=\left(\right.$ brachytherap $^{\star}$ OR chemoradi ${ }^{\star}$ OR chemo-radiotherap* OR dosimetric OR EBRT OR DVH OR fractionat* ${ }^{\star}$ OR IGABT OR IGART OR IGRT OR IMRT OR irradiation OR multileaf OR proton-beam OR protontherapy OR radiation OR radiosurgery OR radiother* OR SBRT OR Tomotherapy OR VMAT). The search results were ranked by the number of times the papers were cited to identify the 100 most cited papers.

The publication years, source titles, and countries/regions of the 100 most cited papers were collected with "Analyze Results" from the Web of Science. The total citations and average citations per year were extracted with "Create Citation Report" from the Web of Science.
Research types and research domains were classified independently by two authors, WW and DW. Discrepancies were resolved by the third author XL. Research types were classified into research articles, guidelines (including recommendations and consensus), reviews, meta-analyses, editorials, and letters. Research domains were classified into brachytherapy (including IGABT and non-IGABT), external beam radiation therapy (including IMRT and extended-field irradiation), chemotherapy (including concurrent chemotherapy and neoadjuvant/adjuvant chemotherapy), radiosensitivity and biomarkers associated with the efficacy of radiation therapy, prognostic factors of survival after radiation therapy, adjuvant radiotherapy versus observations after hysterectomy, definitive radiotherapy versus surgery, and others.

\section{RESULTS}

There were 6,218 papers that fulfilled the criterion described above. The 100 most cited papers were identified, and they are listed in Supplementary Table S1. These 100 papers were cited a total of 28,714 times, and the median number of citations was 169.5 times (range: 116-1,700 times). "Concurrent cisplatinbased radiotherapy and chemotherapy for locally advanced cervical cancer" by Rose et al. (6) had both the highest number of total citations (1,700 times) and the highest number of citations per year (77.27 times). Among the 10 most cited papers (Table 1), there were five randomized clinical trials (6-10) and one metaanalysis (11) comparing cisplatin-based concurrent chemoradiotherapy and single radiotherapy in patients with cervical cancer, and there were two recommendations on IGABT released by the gynecological (GYN) GEC ESTRO Working Group $(12,13)$. The other two papers were randomized clinical trials comparing radical surgery and radiotherapy for stages Ib-IIa cervical cancer (14) and comparing adjuvant radiotherapy and no further therapy after radical hysterectomy and pelvic lymphadenectomy in selected patients with cervical cancer (15).

\subsection{Time Distribution and Article Type}

These most cited 100 papers were published between 1990 and 2016. The publication time distribution is shown in Figure 1. The largest number of papers were published during 2005-2009 (26 papers), followed by 2000-2004 (24 papers) and 1995-1999 (20 papers).

Among these papers, there were 83 research articles, 10 guidelines, recommendations, or consensuses, six metaanalyses, and one editorial. Of the 83 research articles, 20 were randomized clinical trials (RCTs). The average citations per paper of RCTs, meta-analysis, and non-RCT research articles were $584.8,357.7$, and 180.5 , respectively.

\subsection{Journals}

As shown in Figure 2, the International Journal of Radiation Oncology Biology Physics published the largest number of papers (40 papers), followed by Radiotherapy and Oncology 
TABLE 1 | The 10 most cited papers in radiotherapy or chemoradiotherapy for cervical cancer from 1990 to 2020 .

\begin{tabular}{|c|c|c|c|c|c|}
\hline Rank & Title & Journal & Year & $\begin{array}{c}\text { Total } \\
\text { citations }\end{array}$ & $\begin{array}{l}\text { Average } \\
\text { citations per } \\
\text { year (rank) }\end{array}$ \\
\hline 2 & $\begin{array}{l}\text { Pelvic radiation with concurrent chemotherapy compared with pelvic and para-aortic radiation for high-risk } \\
\text { cervical cancer }\end{array}$ & N Engl J Med & 1999 & 1,528 & $69.45(2)$ \\
\hline 3 & $\begin{array}{l}\text { Concurrent chemotherapy and pelvic radiation therapy compared with pelvic radiation therapy alone as } \\
\text { adjuvant therapy after radical surgery in high-risk early-stage cancer of the cervix }\end{array}$ & J Clin Oncol & 2000 & 1,343 & $63.95(3)$ \\
\hline 5 & Randomized study of radical surgery versus radiotherapy for stages Ib-lla cervical cancer & Lancet & 1997 & 1,054 & $43.92(9)$ \\
\hline 6 & $\begin{array}{l}\text { Randomized comparison of fluorouracil plus cisplatin versus hydroxyurea as an adjunct to radiation therapy } \\
\text { in stages IIB-IVA carcinoma of the cervix with negative para-aortic lymph nodes: a Gynecologic Oncology } \\
\text { Group and Southwest Oncology Group study }\end{array}$ & J Clin Oncol & 1999 & 1,028 & $46.73(7)$ \\
\hline 7 & $\begin{array}{l}\text { Recommendations from Gynaecological (GYN) GEC ESTRO Working Group (II): concepts and terms in 3D } \\
\text { image-based treatment planning in cervix cancer brachytherapy-3D dose volume parameters and aspects } \\
\text { of } 3 \text { D image-based anatomy, radiation physics, radiobiology }\end{array}$ & $\begin{array}{l}\text { Radiother } \\
\text { Oncol }\end{array}$ & 2006 & 958 & $63.87(4)$ \\
\hline 9 & $\begin{array}{l}\text { Survival and recurrence after concomitant chemotherapy and radiotherapy for cancer of the uterine cervix: a } \\
\text { systematic review and meta-analysis }\end{array}$ & Lancet & 2001 & 750 & $37.5(11)$ \\
\hline 10 & $\begin{array}{l}\text { A randomized trial of pelvic radiation therapy versus no further therapy in selected patients with stage IB } \\
\text { carcinoma of the cervix after radical hysterectomy and pelvic lymphadenectomy: a Gynecologic Oncology } \\
\text { Group study }\end{array}$ & Gynecol Oncol & 1999 & 642 & $29.18(14)$ \\
\hline
\end{tabular}

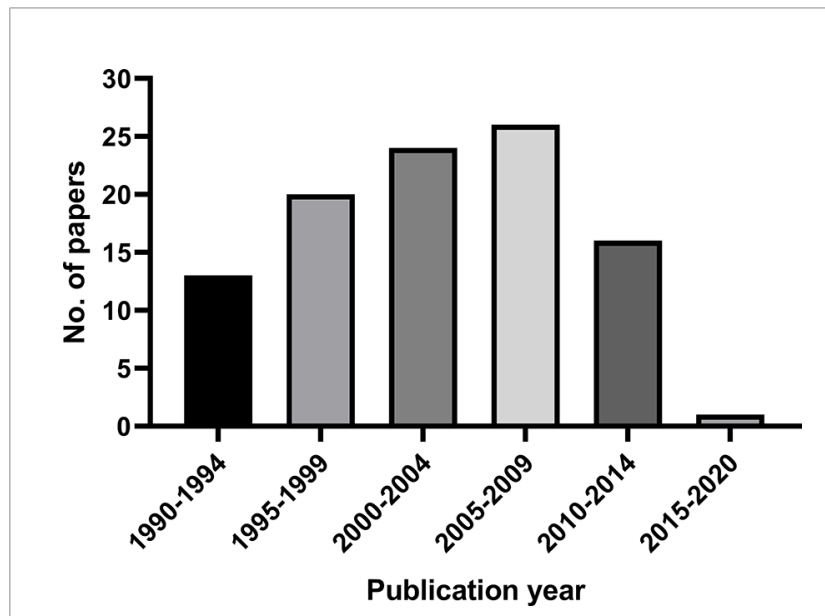

FIGURE 1 | The publication time distribution of the 100 most cited papers in radiotherapy or concurrent chemoradiotherapy for cervical cancer between 1990 and 2020.

(14 papers) and the Journal of Clinical Oncology (12 papers). New England Journal of Medicine (1,202.3 citations per paper) and Lancet (902 citations per paper) had the largest average citations per paper.

\subsection{Countries}

A total of 36 countries or regions participated in the publication of the 100 most cited papers. Most of them are developed countries. As shown in Figure 3, USA contributed the most papers (47 papers), followed by Austria (18 papers), Canada (13 papers), and England (13 papers).

\subsection{Research Domains}

The research domains of these papers are shown in Table 2. In the area of brachytherapy, chemotherapy, and external beam radiation therapy, there were 32 papers (7,594 citations), 21 papers $(10,873$ citations), and 13 papers (4,113 papers), respectively.

In the subdivided research domains, IGABT had the largest number of papers (25 papers). Concurrent chemotherapy was the most cited research domain, with 10,663 total citations and 592.4 citations per paper.

The main research domain in different time periods is shown in Figure 4. From 1990 to 2020, studies on the prognostic factors of survival after radiotherapy, radiosensitivity, and biomarkers associated with the efficacy of radiation therapy decreased. There were more studies on IGABT and IMRT.

\subsubsection{Concurrent Chemotherapy}

All of the 18 papers on concurrent chemotherapy were published between 1998 and 2010. Of them, there were 11 RCTs, six metaanalyses, and one editorial. Eight of them were published in the Journal of Clinical Oncology, followed by the New England Journal of Medicine (four papers) and the Cochrane Database of Systematic Reviews (two papers). The USA participated in 10 of these papers, followed by Canada (five papers), England (four papers), and Thailand (two papers).

\subsubsection{IGABT}

All 25 papers on IGABT were published between 2003 and 2016. Of them, 11 papers were published in the International Journal of Radiation Oncology Biology Physics, 11 papers were published in Radiation and Oncology, two papers were published in Brachytherapy, and one paper was published in Acta Oncology. Austria participated in 17 of these papers, which 


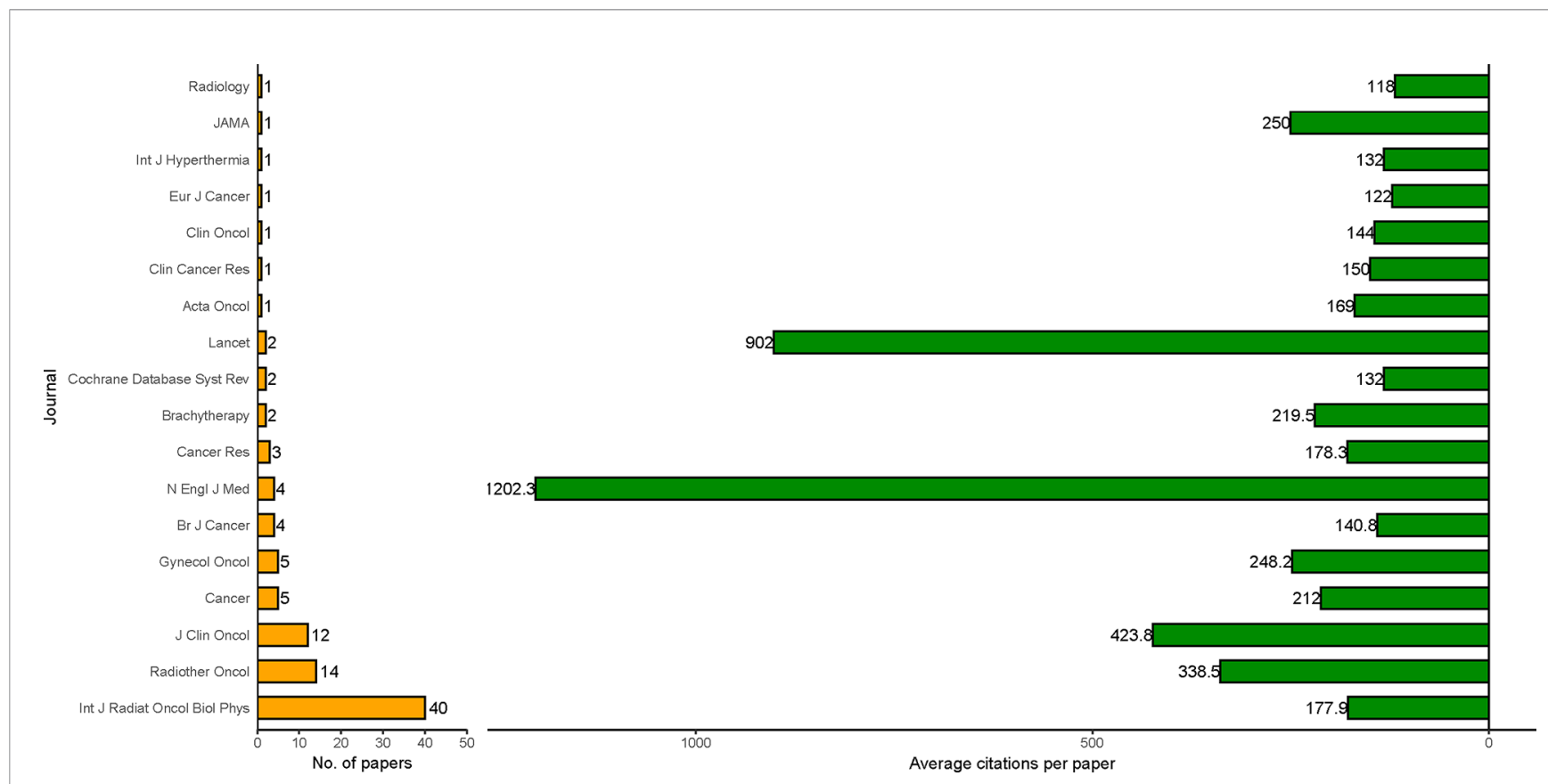

FIGURE 2 | Journals of the 100 most cited papers in radiotherapy or concurrent chemoradiotherapy for cervical cancer between 1990 and 2020 . Average citation paper $=$ total citations/number of papers.
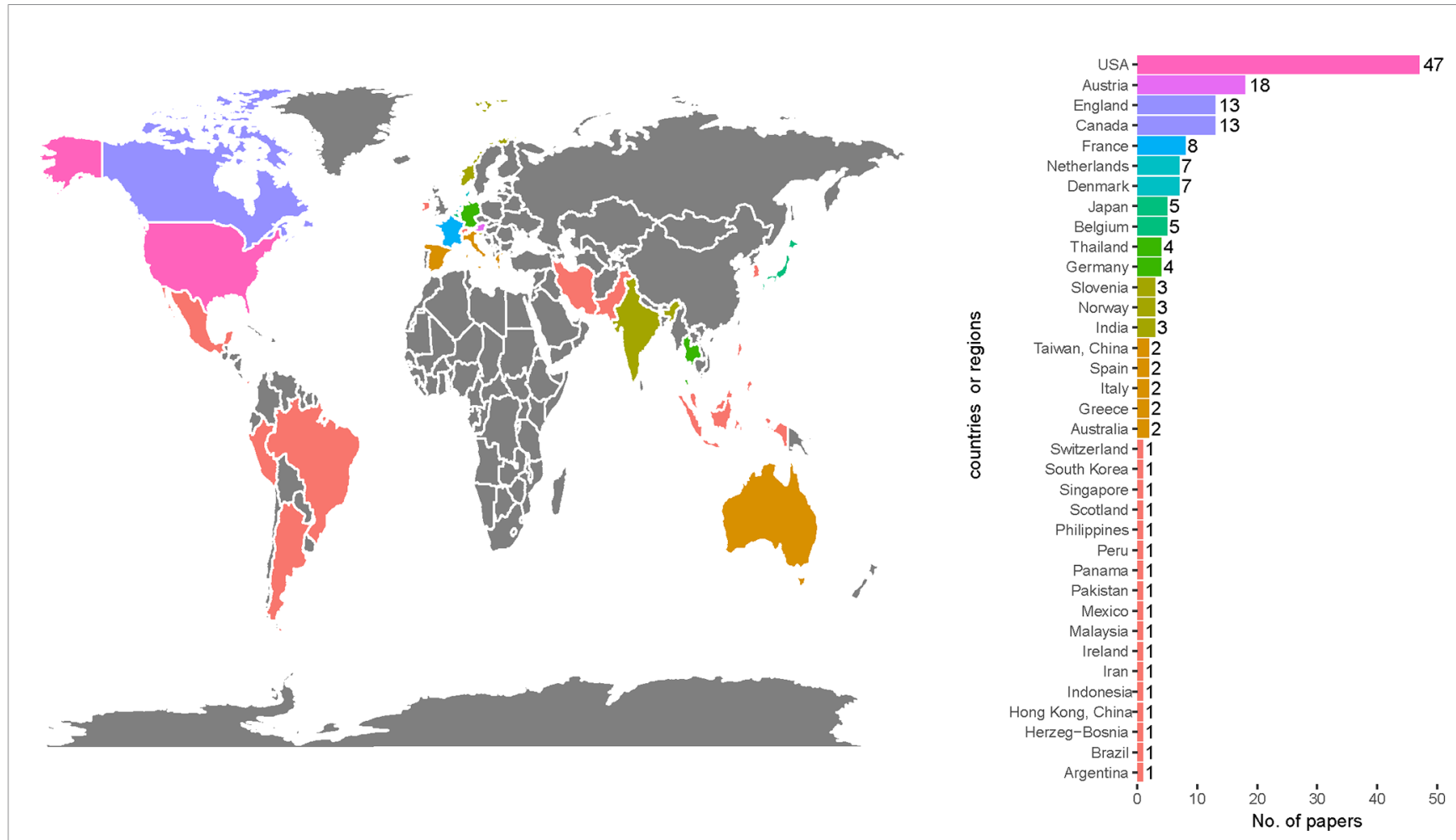

FIGURE 3 | Most frequent countries or regions participating in the 100 most cited papers in radiotherapy or concurrent chemoradiotherapy in cervical cancer between 1990 and 2020. 
TABLE 2 | Research domains of the 100 most cited papers in radiotherapy or concurrent chemoradiotherapy for cervical cancer between 1990 and 2020.

\begin{tabular}{|c|c|c|c|c|}
\hline Research domains & $\begin{array}{l}\text { Number of } \\
\text { articles }\end{array}$ & $\begin{array}{l}\text { Total number } \\
\text { of citations }\end{array}$ & $\begin{array}{l}\text { Average citations } \\
\text { per year (per paper) }\end{array}$ & Publication year \\
\hline Brachytherapy & 32 & 7,594 & 237.3 & 1991-2016 \\
\hline Brachytherapy (non-IGABT) & 8 & 1,436 & 179.5 & 1991-2014 \\
\hline Chemotherapy & 21 & 10,873 & 517.8 & $1991-2011$ \\
\hline Concurrent chemoradiotherapy versus radiotherapy & 18 & 10,663 & 592.4 & 1998-2010 \\
\hline Neoadjuvant/adjuvant chemotherapy & 5 & 1,323 & 264.6 & $1991-2011$ \\
\hline Extended field radiation therapy & 5 & 2,689 & 537.8 & 1995-2008 \\
\hline Radiosensitivity and biomarkers associated with efficacy of radiation therapy & 11 & 2,030 & 184.5 & $1991-2004$ \\
\hline Prognostic factors of survival after radiation therapy & 11 & 2,350 & 213.6 & $1991-2008$ \\
\hline Adjuvant radiotherapy versus observation after hysterectomy & 3 & 1,042 & 347.3 & 1990-2006 \\
\hline Definitive radiotherapy versus surgery & 3 & 1,490 & 49.7 & 1997-2003 \\
\hline Others & 11 & 1,587 & 144.3 & 1992-2009 \\
\hline
\end{tabular}

Some papers belonged to two or more domains.

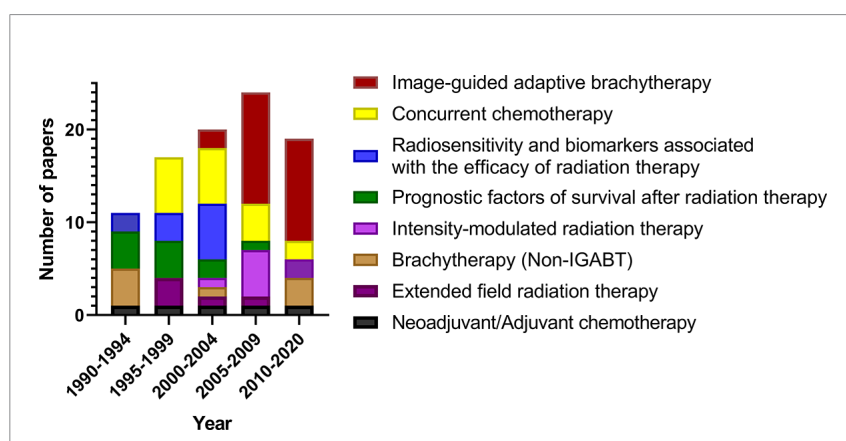

FIGURE 4 | Main research domains in different time periods of the 100 most cited papers in radiotherapy or concurrent chemoradiotherapy for cervical cancer between 1990 and 2020.

was the most, followed by France (seven papers), Denmark (six papers), the USA (six papers), and Belgium (five papers).

\section{DISCUSSION}

Of the 100 most cited papers in radiotherapy for cervical cancer, 18 papers focused on concurrent chemotherapy. The total number of citations of these 18 papers on CCRT versus single radiotherapy was 10,663, which was the largest. Before 1999, single radiotherapy or radiotherapy combined with hydroxyurea was performed for cervical cancer. Between 1999 and 2000, five randomized clinical trials demonstrated that cisplatin-based CCRT was superior to radiotherapy (6-10) (ranked first, cited 1,700 times; ranked second, cited 1,528 times; ranked third, cited 1,343 times; ranked 4th, cited 1,337 times; ranked 6th, cited 1,028 times). In 2001, a meta-analysis demonstrated that CCRT improved the overall survival (OS) and progression-free survival (PFS) of patients with cervical cancer. The absolute benefit of OS and PFS were 12 and 16\%, respectively (11) (ranked 9th, cited 750 times). These studies (6-11) established the role of CCRT in patients with cervical cancer. Twenty years have passed and CCRT is still the standard treatment in patients with locally advanced cervical cancer treated with definitive radiotherapy and for patients with high-risk factors after radical hysterectomy (2). All these 18 papers on CCRT were published before 2010. In the past decade, the role of CCRT has been established and the number of influential studies decreased.

In the domain of concurrent chemotherapy for cervical cancer, journals in the area of oncology or general medicine, the Journal of Clinical Oncology and the New England Journal of Medicine, published the largest number of papers. This is different than the most frequent journals among these 100 papers, the International Journal of Radiation Oncology Biology Physics and Radiation Oncology, two journals focused on radiotherapy. The USA made a great contribution to this area. Institutes or authors from the USA participated in nine of the 17 most cited papers.

In the past several decades, brachytherapy for cervical cancer changed from two-dimensional brachytherapy to MRI or CT-based IGABT. Thirty-two of the 100 most cited papers focused on brachytherapy, which was the largest number. Of them, 25 papers focused on IGABT. The Medical University of Vienna, an institute located in Austria, made great contributions to this area. In the most cited papers in this domain, there were seven recommendations or consensus guidelines: four from the gynecological (GYN) GEC ESTRO Working Group (12, 13, 16, 17) (ranked 7th, cited 958 times; ranked 8th, cited 882 times; ranked 35th, cited 214 times; ranked 53rd, cited 169 times), two from the American Brachytherapy Society (ranked 32nd, cited 225 times; ranked 36th, cited 214 times) $(18,19)$, and one from the Image-Guided Brachytherapy Working Group (20) (ranked 57 th, cited 160 times). These recommendations or guidelines contributed to the progress and standardization of IGABT. RetroEMBRACE, EMBRACE, and the new EMBRACE II were the most impactful studies in the domain of IGABT. The results of retroEMBRACE (21) were reported in 2016 in the 40th most cited paper, with an average of 41.8 citations per year (ranked 10th). As most RetroEMBRACE-, EMBRACE-, and EMBRACE II-based studies were reported after 2015, some of them may become the most cited papers 5 or 10 years later. The International Journal of Radiation Oncology Biology 
Physics and Radiotherapy and Oncology were the most impactful journals for IGABT, publishing 22 of the 25 papers. More impactful papers on brachytherapy in cervical cancer were reported by Tang et al., with the 100 most cited papers in brachytherapy for cervical cancer (22).

IMRT is an important technical advancement in radiotherapy. Compared with conventional or conformal radiotherapy, for cervical cancer, IMRT is superior in sparing the bowel, rectum, and bladder $(23,24)$ (ranked 18th, cited 322 times; ranked 67 th, cited 143 times) and bone marrow (25) (ranked 97th, cited 117 times). IMRT is recommended as adjuvant radiotherapy in patients with cervical cancer $(2,26)$. The Radiation Therapy Oncology Group led an international collaboration of cooperative groups and released a consensus guideline for target volume delineation for IMRT in postoperative radiotherapy in patients with cervical or endometrial cancer (27) (ranked 37th, cited 213 times). However, considering organ motion (28) (ranked 78th, cited 129 times) and tumor regression, IMRT has not been recommended as definitive radiotherapy for patients with cervical cancer for a long time. In 2010, Kidd et al. reported that PET/CT-guided IMRT had improved the survival and was less toxic than non-IMRT radiotherapy in patients with LACC treated with definitive radiotherapy (29) (ranked 96th, cited 117 time). In 2011, the Gyn IMRT Consortium released consensus guidelines for target volume delineation for IMRT in patients with cervical cancer treated with definitive radiotherapy (30) (ranked 38th, cited 212 times). In recent years, additional studies have demonstrated that IMRT is associated with less toxicity and comparable clinical outcomes compared with conventional or conformal radiotherapy in patients with cervical cancer treated with definitive radiotherapy (31-35). In the 2020 ASTRO clinical practice guideline, IMRT is conditionally recommended as definitive radiotherapy for cervical cancer (26).

We identified hotspots in the area of radiotherapy or chemoradiotherapy in cervical cancer using the 100 most cited papers. CCRT and adjuvant radiotherapy improved the survival of patients with cervical cancer. IGABT and IMRT reduce the toxicity of radiotherapy. The local control of LACC is excellent with CCRT, IGABT, and IMRT $(21,35)$. At present, there are more distant failures than local failures (35). Adjuvant chemotherapy, neo-adjuvant chemotherapy, and prophylactic para-aortic lymph node irradiation are potential ways to reduce distant metastasis. Recently, the OUTBACK trial demonstrated that adjuvant chemotherapy following chemoradiotherapy did not improve the survival of patients with LACC (36). The results of the neoadjuvant chemotherapy and prophylactic para-aortic lymph node irradiation were obtained from INTERLACE (NCT01566240) and NCT03955367, etc. Immunotherapy and targeted therapy are also potential ways to prevent distant metastasis of LACC in the future.

This study has some limitations. First, the citations of papers are influenced by many factors, including types of papers, journals, publication time, influence of authors, and even social media exposure. The citation of papers was influenced by the time span after publication. As a result, eight of the 10 most cited papers were published before 2001, and 83 of the 100 most cited papers were published before 2009. No papers published after 2017 were ranked among the top 100 papers. This may lead to missing impactful studies published in the past few years. The number of citations per year was used in the present study to balance the impact of the time span after publication on the selected papers. Second, some highly cited papers are not applicable or insignificant at present. For example, in 1990, Soisson et al. conducted a nonrandomized study that demonstrated that adjuvant radiotherapy following radical hysterectomy had limited benefit for patients with stage IB and IIA cervical cancer compared with radical hysterectomy alone (37) (ranked 77th, cited 130 times). However, adjuvant radiotherapy has been established as the standard treatment after radical hysterectomy for cervical cancer patients meeting the Sedlis criteria. The conclusion of the study of Soisson et al. study may not be applicable at present. Third, only the Web of Science citation indexing database was used to identify the most cited papers. With only 100 papers from the Web of Science, we may miss some influential papers. Fourth, we tried our best to summarize the research domains. However, in the bibliometric analysis, it is difficult to analyze the detailed contents and study design of the papers.

\section{CONCLUSION}

In the present study, we conducted a bibliometric analysis of the 100 most cited papers in radiotherapy or concurrent chemoradiotherapy for cervical cancer in the past 30 years. IGABT and concurrent chemotherapy were the most cited research domains.

\section{DATA AVAILABILITY STATEMENT}

The original contributions presented in the study are included in the article/Supplementary Material. Further inquiries can be directed to the corresponding authors.

\section{AUTHOR CONTRIBUTIONS}

FZ and $\mathrm{KH}$ contributed to the conception of the study. WW and XL wrote the first draft of the manuscript. DW, KR, YZ, ZZ and JQ contributed to the review of literatures. All authors contributed to the article and approved the submitted version.

\section{FUNDING}

This work was supported by the National Natural Science Foundation of China (grant number U19A2064) and the National Key Technologies Research and Development Program of China (grant number 2016YFC0105207).

\section{SUPPLEMENTARY MATERIAL}

The Supplementary Material for this article can be found online at: https://www.frontiersin.org/articles/10.3389/fonc.2021. 642018/full\#supplementary-material 


\section{REFERENCES}

1. Bray F, Ferlay J, Soerjomataram I, Siegel RL, Torre LA, Jemal A. Global Cancer Statistics 2018: GLOBOCAN Estimates of Incidence and Mortality Worldwide for 36 Cancers in 185 Countries. CA Cancer J Clin (2018) 68 (6):394-424. doi: 10.3322/caac.21492

2. National Comprehensive Cancer Network(NCCN). Clinical Practice Guidelines in Oncology, in: Cervical Cancer. Version 1.2021. Available at: https://www.nccn.org/professionals/physician_gls/default.aspx\#cervical (Accessed 21 November, 2020).

3. Pecorelli S. Revised FIGO Staging for Carcinoma of the Vulva, Cervix, and Endometrium. Int J Gynaecol Obstet (2009) 105(2):103-4. doi: 10.1016/ j.ijgo.2009.02.012

4. Oncology FCoG. FIGO Staging for Carcinoma of the Vulva, Cervix, and Corpus Uteri. Int J Gynaecol Obstet (2014) 125(2):97-8. doi: 10.1016/ j.ijgo.2014.02.003

5. Bhatla N, Aoki D, Sharma DN, Sankaranarayanan R. Cancer of the Cervix Uteri. Int J Gynaecol Obstet (2018) 143(Suppl 2):22-36. doi: 10.1002/ ijgo.12611

6. Rose PG, Bundy BN, Watkins EB, Thigpen JT, Deppe G, Maiman MA, et al. Concurrent Cisplatin-Based Radiotherapy and Chemotherapy for Locally Advanced Cervical Cancer. N Engl J Med (1999) 340(15):1144-53. doi: 10.1056/nejm199904153401502

7. Morris M, Eifel PJ, Lu JD, Grigsby PW, Levenback C, Stevens RE, et al. Pelvic Radiation With Concurrent Chemotherapy Compared With Pelvic and ParaAortic Radiation for High-Risk Cervical Cancer. N Engl J Med (1999) 340 (15):1137-43. doi: 10.1056/nejm199904153401501

8. Peters WA, Liu PY, Barrett RJ, Stock RJ, Monk BJ, Berek JS, et al. Concurrent Chemotherapy and Pelvic Radiation Therapy Compared With Pelvic Radiation Therapy Alone as Adjuvant Therapy After Radical Surgery in High-Risk Early-Stage Cancer of the Cervix. J Clin Oncol (2000) 18(8):160613. doi: $10.1200 /$ jco.2000.18.8.1606

9. Keys HM, Bundy BN, Stehman FB, Muderspach LI, Chafe WE, Suggs CL, et al. Cisplatin, Radiation, and Adjuvant Hysterectomy Compared With Radiation and Adjuvant Hysterectomy for Bulky Stage IB Cervical Carcinoma. N Engl J Med (1999) 340(15):1154-61. doi: 10.1056/ nejm199904153401503

10. Whitney CW, Sause W, Bundy BN, Malfetano JH, Hannigan EV, Fowler WC, et al. Randomized Comparison of Fluorouracil Plus Cisplatin Versus Hydroxyurea as an Adjunct to Radiation Therapy in Stage IIB-IVA Carcinoma of the Cervix With Negative Para-Aortic Lymph Nodes: A Gynecologic Oncology Group and Southwest Oncology Group Study. J Clin Oncol (1999) 17(5):1339-48. doi: 10.1200/jco.1999.17.5.1339

11. Green JA, Kirwan JM, Tierney JF, Symonds P, Fresco L, Collingwood M, et al. Survival and Recurrence After Concomitant Chemotherapy and Radiotherapy for Cancer of the Uterine Cervix: A Systematic Review and Meta-Analysis. Lancet (2001) 358(9284):781-6. doi: 10.1016/s0140-6736(01)05965-7

12. Potter R, Haie-Meder C, Van Limbergen E, Barillot I, De Brabandere M, Dimpoulos J, et al. Recommendations From Gynaecological (GYN) GEC ESTRO Working Group (II): Concepts and Terms in 3D Image-Based Treatment Planning in Cervix Cancer Brachytherapy - 3D Dose Volume Parameters and Aspects of 3D Image-Based Anatomy, Radiation Physics, Radiobiotogy. Radiother Oncol (2006) 78(1):67-77. doi: 10.1016/j.radonc. 2005.11.014

13. Haie-Meder C, Potter R, Van Limbergen E, Briot E, De Brabandere M, Dimopoulos J, et al. Recommendations From Gynaecological (GYN) GECESTRO Working Group* (I): Concepts and Terms in 3D Image Based 3D Treatment Planning in Cervix Cancer Brachytherapy With Emphasis on MRI Assessment of GTV and CTV. Radiother Oncol (2005) 74(3):235-45. doi: 10.1016/j.radonc.2004.12.015

14. Landoni F, Maneo A, Colombo A, Placa F, Milani R, Perego P, et al. Randomised Study of Radical Surgery Versus Radiotherapy for Stage Ib-IIa Cervical Cancer. Lancet (1997) 350(9077):535-40. doi: 10.1016/s0140-6736 (97)02250-2

15. Sedlis A, Bundy BN, Rotman MZ, Lentz SS, Muderspach LI, Zaino RJ. A Randomized Trial of Pelvic Radiation Therapy Versus No Further Therapy in Selected Patients With Stage is Carcinoma of the Cervix After Radical Hysterectomy and Pelvic Lymphadenectomy: A Gynecologic Oncology
Group Study. Gynecol Oncol (1999) 73(2):177-83. doi: 10.1006/ gyno.1999.5387

16. Dimopoulos JCA, Petrow P, Tanderup K, Petric P, Berger D, Kirisits C, et al. Recommendations From Gynaecological (GYN) GEC-ESTRO Working Group (IV): Basic Principles and Parameters for MR Imaging Within the Frame of Image Based Adaptive Cervix Cancer Brachytherapy. Radiother Oncol (2012) 103(1):113-22. doi: 10.1016/j.radonc.2011.12.024

17. Hellebust TP, Kirisits C, Berger D, Perez-Calatayud J, De Brabandere M, De Leeuw A, et al. Recommendations From Gynaecological (GYN) GEC-ESTRO Working Group: Considerations and Pitfalls in Commissioning and Applicator Reconstruction in 3D Image-Based Treatment Planning of Cervix Cancer Brachytherapy. Radiother Oncol (2010) 96(2):153-60. doi: 10.1016/j.radonc.2010.06.004

18. Viswanathan AN, Thomadsen B, Amer Brachytherapy S. American Brachytherapy Society Consensus Guidelines for Locally Advanced Carcinoma of the Cervix. Part I: General Principles. Brachytherapy (2012) 11(1):33-46. doi: 10.1016/j.brachy.2011.07.003

19. Viswanathan AN, Beriwal S, De Los Santos JF, Demanes DJ, Gaffney D, Hansen J, et al. American Brachytherapy Society Consensus Guidelines for Locally Advanced Carcinoma of the Cervix. Part II: High-Dose-Rate Brachytherapy. Brachytherapy (2012) 11(1):47-52. doi: 10.1016/j.brachy.2011.07.002

20. Nag S, Cardenes H, Chang S, Das IJ, Erickson B, Ibbott GS, et al. Proposed Guidelines for Image-Based Intracavitary Brachytherapy for Cervical Carcinoma: Report From Image-Guided Brachytherapy Working Group. Int J Radiat Oncol Biol Phys (2004) 60(4):1160-72. doi: 10.1016/j.ijrobp.2004.04.032

21. Sturdza A, Potter R, Fokdal LU, Haie-Meder C, Tan LT, Mazeron R, et al. Image Guided Brachytherapy in Locally Advanced Cervical Cancer: Improved Pelvic Control and Survival in RetroEMBRACE, a Multicenter Cohort Study. Radiother Oncol (2016) 120(3):428-33. doi: 10.1016/j.radonc.2016.03.011

22. Tang X, Zhao Z, Zhao H, Mao Z. The 100 Most Cited Articles in Cervical Cancer Brachytherapy. Brachytherapy (2020) 19(2):181-93. doi: 10.1016/ j.brachy.2019.11.006

23. Portelance L, Chao KSC, Grigsby PW, Bennet H, Low D. Intensity-Modulated Radiation Therapy (IMRT) Reduces Small Bowel, Rectum, and Bladder Doses in Patients With Cervical Cancer Receiving Pelvic and Para-Aortic Irradiation. Int J Radiat Oncol Biol Phys (2001) 51(1):261-6. doi: 10.1016/ s0360-3016(01)01664-9

24. van de Bunt L, van der Heide UA, Ketelaars M, de Kort GA, JurgenliemkSchulz IM. Conventional, Conformal, and Intensity-Modulated Radiation Therapy Treatment Planning of External Beam Radiotherapy for Cervical Cancer: The Impact of Tumor Regression. Int J Radiat Oncol Biol Phys (2006) 64(1):189-96. doi: 10.1016/j.ijrobp.2005.04.025

25. Mell LK, Tiryaki H, Ahn KH, Mundt AJ, Roeske JC, Aydogan B. Dosimetric Comparison of Bone Marrow-Sparing Intensity-Modulated Radiotherapy Versus Conventional Techniques for Treatment of Cervical Cancer. Int J Radiat Oncol Biol Phys (2008) 71(5):1504-10. doi: 10.1016/j.jijrobp.2008.04.046

26. Chino J, Annunziata CM, Beriwal S, Bradfield L, Erickson BA, Fields EC, et al. Radiation Therapy for Cervical Cancer: Executive Summary of an ASTRO Clinical Practice Guideline. Pract Radiat Oncol (2020) 10(4):220-34. doi: 10.1016/j.prro.2020.04.002

27. Small W Jr, Mell LK, Anderson P, Creutzberg C, De Los Santos J, Gaffney D, et al. Consensus Guidelines for Delineation of Clinical Target Volume for Intensity-Modulated Pelvic Radiotherapy in Postoperative Treatment of Endometrial and Cervical Cancer. Int J Radiat Oncol Biol Phys (2008) 71 (2):428-34. doi: 10.1016/j.ijrobp.2007.09.042

28. Chan P, Dinniwell R, Haider MA, Cho YB, Jaffray D, Lockwood G, et al. Inter-and Intrafractional Tumor and Organ Movement in Patients With Cervical Cancer Undergoing Radiotherapy: A Cinematic-MRI Point-of-Interest Study. Int J Radiat Oncol Biol Phys (2008) 70(5):1507-15. doi: 10.1016/ j.jirobp.2007.08.055

29. Kidd EA, Siegel BA, Dehdashti F, Rader JS, Mutic S, Mutch DG, et al. Clinical Outcomes of Definitive Intensity-Modulated Radiation Therapy With Fluorodeoxyglucose-Positron Emission Tomography Simulation in Patients With Locally Advanced Cervical Cancer. Int J Radiat Oncol Biol Phys (2010) 77(4):1085-91. doi: 10.1016/j.ijrobp.2009.06.041

30. Lim K, Small WJr., Portelance L, Creutzberg C, Jurgenliemk-Schulz IM, Mundt A, et al. Consensus Guidelines for Delineation of Clinical Target Volume for Intensity-Modulated Pelvic Radiotherapy for the Definitive 
Treatment of Cervix Cancer. Int J Radiat Oncol Biol Phys (2011) 79(2):348-55. doi: 10.1016/j.ijrobp.2009.10.075

31. Lin Y, Chen K, Lu Z, Zhao L, Tao Y, Ouyang Y, et al. Intensity-Modulated Radiation Therapy for Definitive Treatment of Cervical Cancer: A MetaAnalysis. Radiat Oncol (2018) 13(1):177. doi: 10.1186/s13014-018-1126-7

32. Naik A, Gurjar OP, Gupta KL, Singh K, Nag P, Bhandari V. Comparison of Dosimetric Parameters and Acute Toxicity of Intensity-Modulated and Three-Dimensional Radiotherapy in Patients With Cervix Carcinoma: A Randomized Prospective Study. Cancer Radiother (2016) 20(5):370-6. doi: 10.1016/j.canrad.2016.05.011

33. Yu C, Zhu W, Ji Y, Guo J, Pan P, Han J, et al. A Comparative Study of Intensity-Modulated Radiotherapy and Standard Radiation Field With Concurrent Chemotherapy for Local Advanced Cervical Cancer. Eur J Gynaecol Oncol (2015) 36(3):278-82. doi: 10.12892/ejgo2622.2015

34. Gandhi AK, Sharma DN, Rath GK, Julka PK, Subramani V, Sharma S, et al. Early Clinical Outcomes and Toxicity of Intensity Modulated Versus Conventional Pelvic Radiation Therapy for Locally Advanced Cervix Carcinoma: A Prospective Randomized Study. Int J Radiat Oncol Biol Phys (2013) 87(3):542-8. doi: 10.1016/j.ijrobp.2013.06.2059

35. Wang W, Zhang F, Hu K, Hou X. Image-Guided, Intensity-Modulated Radiation Therapy in Definitive Radiotherapy for 1433 Patients With Cervical Cancer. Gynecol Oncol (2018) 151(3):444-8. doi: 10.1016/j.ygyno.2018.09.024

36. Mileshkin LR, Moore KN, Barnes E, Gebski V, Narayan K, Bradshaw N, et al. Adjuvant Chemotherapy Following Chemoradiation as Primary Treatment for Locally Advanced Cervical Cancer Compared to Chemoradiation Alone: The Randomized Phase III OUTBACK Trial (ANZGOG 0902, RTOG 1174,
NRG 0274), ASCO Annual Meeting 2021, Abstract LBA3. Available at: https://s3.amazonaws.com/files.oncologymeetings.org/prod/s3fs-public/ 2021-06/AM-2021-LBAs-Final.pdf?null (Accessed 26 Aug, 2021).

37. Soisson AP, Soper JT, Clarkepearson DL, Berchuck A, Montana G, Creasman WT. Adjuvant Radiotherapy Following Radical Hysterectomy for Patients With Stage IB and IIA Cervical Cancer. Gynecol Oncol (1990) 37(3):390-5. doi: 10.1016/0090-8258(90)90374-t

Conflict of Interest: The authors declare that the research was conducted in the absence of any commercial or financial relationships that could be construed as a potential conflict of interest.

Publisher's Note: All claims expressed in this article are solely those of the authors and do not necessarily represent those of their affiliated organizations, or those of the publisher, the editors and the reviewers. Any product that may be evaluated in this article, or claim that may be made by its manufacturer, is not guaranteed or endorsed by the publisher.

Copyright () 2021 Wang, Liu, Wang, Ren, Zhou, Zhou, Qiu, Zhang and Hu. This is an open-access article distributed under the terms of the Creative Commons Attribution License (CC BY). The use, distribution or reproduction in other forums is permitted, provided the original author(s) and the copyright owner(s) are credited and that the original publication in this journal is cited, in accordance with accepted academic practice. No use, distribution or reproduction is permitted which does not comply with these terms. 